\title{
Desafios às açóes educativas das Equipes de Saúde Bucal na Atenção Primária à Saúde: táticas, saberes e técnicas
}

\section{| ${ }^{1}$ Paula Roberta da Conceição Brasil, ${ }^{2}$ Adriano Maia dos Santos |}

Resumo: Estudo sobre as práticas educativas das Equipes de Saúde Bucal na Atenção Primária à Saúde em Salvador, Bahia. A pesquisa teve como objetivos a análise das táticas das Equipes de Saúde Bucal para envolvimento da comunidade nas práticas de educação em saúde e discutir os saberes e técnicas desenvolvidas nas açōes educativas. Optou-se pela abordagem qualitativa, por meio de 22 entrevistas semiestruturadas, envolvendo sete cirurgióes-dentistas, sete auxiliares de saúde bucal, seis gerentes das unidades de saúde e dois gestores distritais. A análise de conteúdo temática orientou a análise e interpretação dos resultados. $\mathrm{O}$ modelo educativo estava centrado no saber do cirurgião-dentista, revelado no caráter prescritivo e burocrático das atividades desenvolvidas na comunidade. Tais práticas educativas tendem a não incentivar a autonomia dos usuários, fazendo-os, de certa forma, reféns do modelo hegemônico de produção do cuidado focado na doença.

> Palavras-chave: educação em saúde; Estratégia Saúde da Família; sistemas locais de saúde; atenção básica; educação.
${ }^{1}$ Universidade Estadual de Feira de Santana, Departamento de Saúde. Feira de Santana-BA, Brasil (prcbrasil@gmail.com). ORCID: 0000-0002-8542-4886

2 Universidade Federal da Bahia, Instituto Multidisciplinar em Saúde. Vitória da Conquista-BA, Brasil (maiaufba@ufba.br). ORCID: 0000-0001-9718-1562
Recebido em: 10/02/2018 Revisado em: 22/06/2018 Aprovado em: 08/10/2018 


\section{Introdução}

A educação em saúde é uma prática social com potência para desenvolver a reflexão e a consciência crítica das pessoas sobre seus problemas em saúde (FALKENBERG et al., 2014; GAZZINELLI et al., 2005). Tal compreensão aposta na educação numa perspectiva crítico-reflexiva, ou seja, reconhecendo-a como dispositivo capaz de mudar as açóes humanas, por meio da luta pela cidadania, alicerçada em elementos pedagógicos que tenham as pessoas em primeiro lugar e o compromisso ético-político com a desalienação e superação das condições de opressão (FREIRE, 2011a; FREIRE, 2011b).

Trata-se, por conseguinte, de identificar as facetas da educação e sua possibilidade de criar condiçôes necessárias para realização de transformações indispensáveis, mas, também, reconhecê-la dialeticamente como parte das estruturas de poder político e econômico (BRANDÃO, 2004). Deste modo, os usos sociais da ciência (BOURDIEU, 2004), enquanto campo de disputas, guiam as práticas dos diferentes sujeitos sociais e, no caso dos profissionais da saúde, por meio de seu capital científico, agem na definição dos modos de viver da sociedade, atribuindo autoridade às ciências médicas na definição do que é normal ou patológico (COELHO; ALMEIDA FILHO, 1999). Nesta perspectiva, o processo de educação em saúde também pode ser um instrumento de dominação, de afirmação de um saber biomédico que responsabiliza os indivíduos pela redução dos riscos à saúde, desconsidera os determinantes sociais e cinde o sentido da integralidade do cuidado (ALBUQUERQUE; STOTZ, 2004).

$\mathrm{Na}$ outra margem, a educação em saúde torna-se um processo de ensinoaprendizagem, em permanente construção, que se dá no cotidiano do fazer dos profissionais e na interface das necessidades das pessoas, buscando compartilhar saberes da experiência da populaçáo com os conhecimentos cunhados na academia (CAMPOS; CUNHA; FIGUEIREDO, 2013). Em contraposição à medicalização social e progressiva expansão das intervençôes da biomedicina sobre os corpos e comportamentos humanos (TESSER, 2006), a educação em saúde seria o dispositivo para mitigar ou reverter os danos iatrogênicos (clínico, social ou cultural) derivados das práticas profissionais centradas na doença (TESSER, 2010; CONRAD, 2007). Porquanto, a educação em saúde, na sua dimensão "popular", seria "um instrumento fundamental na construção histórica de uma medicina integral”, por meio, da 
valorização de "saberes e práticas dos sujeitos usualmente desconsiderados devido a sua origem popular" (VASCONCELOS, 2004, p.74).

No campo da saúde bucal, a medicalização motiva, igualmente, uma demanda crescente e potencialmente infinita por serviços, produtos e procedimentos odontológicos que, a serviço do mercado, geram problemas que atravessam a organização e o cotidiano dos serviços e das práticas profissionais (BOTAZZO, 2006; TESSER et al., 2015). Em contraposição, a inserção da Equipe de Saúde Bucal (EqSB), na Estratégia Saúde da Família (ESF), possibilitou a criação de fértil espaço de práticas e relaçôes para reorientação do processo de trabalho, bem como a própria atuação do cirurgião-dentista no âmbito dos serviços de saúde, na perspectiva da saúde bucal coletiva (RODRIGUES; ASSIS, 2009; SOUZA; RONCALLI, 2007). Para tanto, o cuidado em saúde bucal passou a exigir a conformação de uma equipe de trabalho que dê respostas às demandas da população, no intuito de ampliar o acesso às açôes e aos serviços de promoção da saúde, prevenção de doenças e recuperação da saúde bucal, seja em caráter coletivo ou individual, mediante o estabelecimento de vínculo territorial (NARVAI; FRAZÃO, 2008; SANTOS; ASSIS, 2010).

Diante dessa compreensão, a educação em saúde é encarada como uma ação complexa e carregada de desafios ambíguos, que ocorre, cotidianamente, no nível das relaçôes sociais entre os profissionais movidos pelo saber científico e a comunidade por meio do senso comum e dos saberes tradicionais (LABBATE, 1994). Tendo em vista que as açôes desenvolvidas na ESF devem envolver práticas de promoção da saúde e práticas curativas, a educação em saúde constituiu-se numa prática dialógica a ser desenvolvida por diferentes profissionais das Equipes de Saúde da Família (EqSF), seja no âmbito individual da clínica ou coletivo no território (ALVES, 2005).

Diante disto, a mudança no modo de agir e compreender o processo de trabalho clínico e educativo precisa ser mote de reflexão, também, entre os trabalhadores que compóem a EqSB, para que o cuidado seja inerente ao saber-fazer dos profissionais e obstáculos, como práticas verticalizadas, açôes não dialógicas e posturas autoritárias sejam superados (AYRES, 2009; PINHEIRO et al., 2006; ALBUQUERQUE; STOTZ, 2004).

Por este prisma, buscou-se analisar as táticas das Equipes de Saúde Bucal para envolvimento da comunidade nas práticas educativas em saúde e discutir as práticas pedagógicas (saberes e técnicas) desenvolvidas nas ações educativas. 


\section{Metodologia}

Trata-se de estudo de caso (YIN, 2005), de cunho qualitativo (FLICK, 2009), realizado no Distrito Sanitário de Cajazeiras, com aproximadamente $172 \mathrm{mil}$ habitantes, localizado no município de Salvador, Bahia. A investigação teve como lócus as Equipes de Saúde da Família (EqSF) com Equipe de Saúde Bucal (EqSB) implantada. ${ }^{1}$

Nada obstante, ainda que a gênese do processo de territorializaçáo tenha sido por meio do distrito sanitário, na atualidade, a proposta de espacialidade na saúde, em Salvador, aproxima-se da versão topográfico-burocrática, que corresponde "à desconcentração e rearranjo das unidades de saúde sem necessariamente mudar o modelo de produção do cuidado" (MENDES, 1993). Nesta perspectiva, o município foi recortado em 12 distritos sanitários, sendo o Distrito Cajazeiras um deles (quadro 1), com oito Unidades de Saúde da Família (USF), perfazendo 26 EqSF e 18 EqSB (SALVADOR, 2014).

Quadro 1. Relação proporcional da quantidade de Equipe de Saúde da Família (EqSF) e Equipe de Saúde Bucal (EqSB) no Distrito Sanitário Cajazeiras, em Salvador, Bahia

\begin{tabular}{|l|c|c|c|}
\hline $\begin{array}{c}\text { Unidade de Saúde } \\
\text { da Família (USF) }\end{array}$ & Número de EqSF & Número de EqSB & $\begin{array}{c}\text { Proporçáo } \\
\text { EqSF/EqSB }\end{array}$ \\
\hline USF A & $4 \mathrm{EqSF}$ & $2 \mathrm{EqSB}$ & $2: 1$ \\
\hline USF B & $4 \mathrm{EqSF}$ & $2 \mathrm{EqSB}$ & $2: 1$ \\
\hline USF C & $3 \mathrm{EqSF}$ & $2 \mathrm{EqSB}$ & $3: 2$ \\
\hline USF D & $2 \mathrm{EqSF}$ & $2 \mathrm{EqSB}$ & $1: 1$ \\
\hline USF E & $4 \mathrm{EqSF}$ & $2 \mathrm{EqSB}$ & $2: 1$ \\
\hline USF F & $4 \mathrm{EqSF}$ & $4 \mathrm{EqSB}$ & $1: 1$ \\
\hline USF G & $2 \mathrm{EqSF}$ & $2 \mathrm{EqSB}$ & $1: 1$ \\
\hline USF H & $3 \mathrm{EqSF}$ & $2 \mathrm{EqSB}$ & $3: 2$ \\
\hline Total & $26 \mathrm{EqSF}$ & $18 \mathrm{EqSB}$ & - \\
\hline
\end{tabular}

Fonte: Secretaria Municipal de Saúde de Salvador.

Para compreensão das práticas de educação em saúde realizadas pelas EqSB, foram interrogados os participantes responsáveis pela gestão distrital da saúde 
bucal, gerência das USF e assistência à saúde bucal. Para seleção dos participantes $\mathrm{da}$ assistência dos serviços, os quais pertenciam à EqSB, realizaram-se dois procedimentos:

1) sorteio de duas EqSB em cada USF, intencionando contemplar um representante por equipe. Para tanto, sorteou-se o nome do cirurgiáo-dentista (CD) de uma dada EqSB e, imediatamente, o auxiliar da saúde bucal (ASB) da outra equipe era contemplado;

2) levou-se em consideração uma amostragem por redundância de informação, ou seja, por critério de saturação empírica para definição e interrupção da coleta de dados (FONTANELLA et al., 2011). Portanto, mesmo com o sorteio de 18 participantes $(\mathrm{CD}+\mathrm{ASB})$, suspendeu-se a coleta, para esse grupo, na $14^{\mathrm{a}}$ entrevista. Para os participantes da gestão dos serviços, não houve necessidade de sorteio, sendo utilizada, exclusivamente, a saturação.

Para participação na investigação, estabeleceram-se os seguintes critérios:

1) EqSF completas com médico e enfermeiro; e

2) EqSB com, no mínimo, 12 meses de implantação e funcionamento. Os participantes selecionados compuseram dois grupos distintos, segundo processo de trabalho no SUS (assistência ou gestão dos serviços):

Grupo I - EqSB (CD e ASB): grupo formado por profissionais que exercem a prática da assistência à saúde bucal no cotidiano da ESF. Tais sujeitos operam na micropolítica do trabalho em saúde, por meio da promoção, prevenção, cura e reabilitação, fazendo uso de distintas tecnologias para produção do cuidado. Grupo II - gestores: grupo formado por profissionais que exercem as funçóes de coordenação, planejamento, acompanhamento, monitoramento ou avaliação da saúde, do ponto de vista local (nas USF) e distrital (no distrito sanitário). Este grupo foi composto pelos gerentes das USF, cirurgião-dentista distrital e cogestor distrital da saúde bucal.

As fontes de informação e técnicas de produção de dados foram: 22 entrevistas semiestruturadas (sete cirurgióes-dentistas, sete auxiliares de saúde bucal, seis gerentes das unidades de saúde e dois gestores distritais). A produção de dados ocorreu entre julho e setembro de 2015. 
O roteiro de entrevista utilizado foi dividido em quatro componentes temáticos e desmembrado em indicadores temáticos para estimular a produção dos dados e definição das categorias empíricas (quadro 2).

Quadro 2. Categorias Temáticas

\begin{tabular}{|c|c|c|}
\hline Componente temático & Indicador temático & Categoria temática \\
\hline $\begin{array}{l}\text { Atividades educativas } \\
\text { realizadas por Equipe de } \\
\text { Saúde Bucal (EqSB) }\end{array}$ & $\begin{array}{l}\text { - Modo de organizaçáo } \\
\text { - Modo de acompanhamento e } \\
\text { estímulo pela gestão municipal } \\
\text { - Estratégia municipal para incentivar } \\
\text { as açóes educativas nas EqSB } \\
\text { - Incentivos e apoio da gestão } \\
\text { municipal } \\
\text { - O que a EqSB espera com as práticas } \\
\text { educativas desenvolvidas na área }\end{array}$ & \multirow{3}{*}{$\begin{array}{l}\text { Táticas para } \\
\text { envolvimento da } \\
\text { comunidade nas } \\
\text { práticas de educação } \\
\text { em saúde no fazer } \\
\text { cotidiano das Equipe } \\
\text { de Saúde Bucal }\end{array}$} \\
\hline $\begin{array}{l}\text { Estratégias, utilizadas } \\
\text { pela EqSB, para } \\
\text { estimular a comunidade } \\
\text { a participar das práticas } \\
\text { de educaçáo em saúde }\end{array}$ & $\begin{array}{l}\text { - Formação dos cirurgióes-dentistas } \\
\text { - Desafios/dificuldades } \\
\text { - Facilitadores/avanços } \\
\text { - Panorama de organização/ } \\
\text { participaçáo da comunidade }\end{array}$ & \\
\hline $\begin{array}{l}\text { Participação de outros } \\
\text { profissionais nas } \\
\text { atividades sobre o tema } \\
\text { saúde bucal }\end{array}$ & $\begin{array}{l}\text { - Profissionais envolvidos } \\
\text { - Atividades realizadas } \\
\text { - Modo de participação }\end{array}$ & \\
\hline $\begin{array}{l}\text { Estratégias utilizadas } \\
\text { pela EqSB para } \\
\text { construçáo das } \\
\text { atividades educativas }\end{array}$ & $\begin{array}{l}\text { - Temas escolhidos e modo de escolha } \\
\text { - Locais onde são desenvolvidas e } \\
\text { frequência das atividades } \\
\text { - Quem realiza e como são } \\
\text { operacionalizadas } \\
\text { - Recursos didáticos utilizados } \\
\text { - Preparo dos profissionais para as } \\
\text { açóes educativas }\end{array}$ & \multirow{2}{*}{$\begin{array}{l}\text { Saberes e técnicas } \\
\text { mobilizadas para } \\
\text { construção das } \\
\text { intervençóes } \\
\text { educativas: } \\
\text { transmissão de } \\
\text { conteúdos para } \\
\text { disciplinar os corpos }\end{array}$} \\
\hline $\begin{array}{l}\text { Participação da EqSB } \\
\text { em atividades educativas } \\
\text { não relacionadas ao tema } \\
\text { saúde bucal }\end{array}$ & $\begin{array}{l}\text { - Atividades realizadas } \\
\text { - Modo de participaçáo }\end{array}$ & \\
\hline
\end{tabular}


Os dados foram apresentados em fragmentos representativos e discutidos em sínteses narrativas que traduzem as categorias temáticas. Para tratamento dos dados empíricos, optou-se pela análise de conteúdo temática (MINAYO, 2014). Os trechos com as estruturas relevantes e ideias centrais (núcleos de sentido) foram selecionados, agrupados e classificados em duas categorias temáticas:

1 - Táticas para envolvimento da comunidade nas práticas de educação em saúde no fazer cotidiano das Equipes de Saúde Bucal;

2 - Saberes e técnicas mobilizadas para construção das intervençôes educativas: transmissão de conteúdos para disciplinar os corpos.

A pesquisa foi aprovada em Comitê de Ética em Pesquisa (Parecer no 1.101.690), Universidade Estadual de Feira de Santana, em 10 de junho de 2015.

\section{Resultados e discussão}

Táticas para envolvimento da comunidade nas práticas de educação em saúde no fazer cotidiano das Equipes de Saúde Bucal

A formação acadêmica de muitos profissionais pode influenciar para que predomine o perfil educacional mais vertical e conservador, sem compreender a importância da valorização da opiniáo da comunidade sobre as escolhas das açôes e serviços de saúde realizados nas suas práticas cotidianas (CECCIM; FEUERWERKER, 2004; SANTOS et al., 2006).

Em algumas falas, por exemplo, a grande expectativa e preocupação dos profissionais restringia-se a querer que as pessoas absorvessem todo o conteúdo transmitido e, assim, estivessem aptas a multiplicar as informaçóes para outros usuários. Tal postura não se caracteriza necessariamente como culpa dos profissionais, visto que muitos foram capturados, no processo formativo, pelo modelo biomédico e da "história natural da doença" (ALMEIDA FILHO; JUCÁ, 2002; PAGLIOSA; ROS, 2008). Sendo assim, muitos profissionais remetem-se, acriticamente, à técnica da educação bancária, por perceber os indivíduos como caixas receptoras de saberes cientificamente estabelecidos e reconhecidos como verdade em detrimento dos saberes populares (FREIRE, 2011a).

A gente espera que seja absorvido o que a gente está passando, que as pessoas apliquem no dia a dia, pois não adianta a gente ficar falando se as pessoas não estão trazendo isso para o seu cotidiano, esperamos que surta efeito (Grupo I - CD, ent. 1). 
O intuito é esse, que um que esteja aqui leve para a família, para dentro de casa, e possa, assim, estar multiplicando nossa ação (Grupo I - CD, ent. 3).

Por outro lado, entrevistados também relataram que, em uma das USF do estudo, a comunidade estava bastante participativa, quando as açôes estavam relacionadas às práticas lúdicas ou artesanais, sendo, algumas vezes, protagonistas dessas ações.

Eles participam, dão sugestão, trazem instrumento musical, principalmente nesta parte artística. Tem uma pessoa que dança, outra toca, eles dão sugestão mais nessa parte, não muito do conteúdo em si, do que vai ser projetado referente à parte de informaçóes mesmo (Grupo I - CD, ent. 5).

Todavia, quando as açôes estavam relacionadas ao ato de opinar, sugerir ou destacar as necessidades de saúde e vulnerabilidades locais, os usuários apresentavam pouco interesse, sendo este um aspecto predominante em grande parte das falas dos entrevistados. Em alguns momentos, houve discreta tentativa de participação social das comunidades, com envolvimento dos líderes comunitários nas atividades da ESF. Contudo, eram situaçôes pontuais, que, no contexto das falas dos entrevistados, aparentavam-se como uma relaçáo hierarquizada entre educadores e educandos. De forma predominante, constataram-se usuários "passivos" com suas realidades, ainda que não fossem as melhores condiçôes possivelmente desejadas por eles, porém, participativos nos eventos relacionados às comemoraçôes com danças, músicas e festas.

As ações lúdicas são facilitadoras das práticas educativas, pois constituem importantes estratégias para estimular o ensino e aprendizagem, com efeito significativo, prazeroso e satisfatório para os sujeitos envolvidos no processo. Contudo, o lúdico desprovido de conteúdo não muda ideias, não traz transformações, tão pouco estimula o indivíduo a transcender a barreira da alienação para um conhecimento libertador e transformador. Neste sentido, a crítica à ludicidade é para que esta não seja apenas um instrumento de animação populacional, mas que contribua para a interação entre profissionais da saúde e usuários, estimulando a troca de saberes no fazer coletivo, bem como reduzindo as distâncias entre conhecimento científico e popular.

Cabe destacar a fala de um dos entrevistados, reconhecendo a fragilidade do processo educativo nas comunidades assistidas pelas práticas e serviços dos profissionais da EqSF, bem como suas repercussões sobre as ações de construçôes sociais. 


\begin{abstract}
Para saber o que vai pedir, ele precisa ser educado de lá de baixo. A populaçáo não é educada ainda. Ela não tem o conhecimento, não sabe a informação, não é questão de burrice, mas questão de ignorância. Ela ignora o que pode pedir, ela ignora o que pode exigir do serviço público e, praticamente, ou é induzida pelos profissionais, pelos líderes comunitários, que têm aquela ampla visão de política partidária, ou ficam quietos, simplesmente aceitam (Grupo II, ent. 5).
\end{abstract}

A fala em destaque denuncia uma realidade social que interfere diretamente nas práticas educativas e no processo de cuidado da população. Ainda que a intenção seja o estímulo à autonomia dos sujeitos, dando ênfase à responsabilização por seus atos, parcela significativa da população ainda permanece alheia a tais condutas. Devido às desigualdades sociais, que repercutem nas condições de vida dos indivíduos, especialmente quando relacionadas às suas necessidades básicas, como saúde, educação, moradia, segurança, emprego, entre outras.

Outro ponto destacado pelos entrevistados foi a verticalização das açôes educativas, sendo reflexo do dominante modelo hegemônico do cuidado, o qual apresenta como características principais o individualismo, a medicalização dos problemas, o curativismo, o estímulo ao consumismo de procedimentos com ênfase no biológico, que trata a saúde-doença como uma mercadoria e, consequentemente, favorece a passividade e subordinação social (CAMPOS; CUNHA; FIGUEIREDO, 2013). Tal postura compromete o real sentido do processo de educação em saúde nas equipes da ESF, que deveria seguir a política de modelo sanitarista, não se restringindo ao cumprimento de metas, mas ao estímulo do desenvolvimento coletivo, com envolvimento dos usuários nos assuntos relacionados à melhoria da sua qualidade de vida (PAIM, 2012).

Diante das fragilidades registradas e percebidas, cabe colocar em destaque o reconhecimento de parte dos entrevistados sobre a importância das práticas educativas, tendo em vista que estas podem gerar mudança na vida dos usuários. Porém, salienta-se que o estímulo ao desenvolvimento do processo da autonomia dos sujeitos é complexo e tal ato precisa ser reconhecido por todos os envolvidos no processo, sejam profissionais e gestores da saúde, bem como a própria comunidade, compreendendo a singularidade de que a educação é consequência de um pensar livre, sem molduras sociais ou pré-requisitos científicos.

Nessa direção, os discursos também enfocaram o protagonismo dos enfermeiros na organização de açôes na USF. Neste sentido, a EqSB limitava-se, muitas 
vezes, a complementar as abordagens previamente eleitas pela enfermagem, desempenhando um papel coadjuvante, sem indícios de planejamento conjunto ou práticas interdisciplinares.

Quem organiza são os enfermeiros e a gente participa do planejamento deles. Para isso, a
gente tem as reuniốes de equipes, semanais, para justamente estar sempre trazendo essas
informaçôes, debatendo ideias, mas são sempre os enfermeiros que organizam para a
gente participar (Grupo I - CD, ent. 5).
Geralmente a gente tá mais relacionado ao tema saúde bucal, a gente pega os temas que
elas falam [as enfermeiras]. Se elas vão falar sobre alguma doença, a gente fala sobre a re-
percussão daquela doença na boca. A gente geralmente está mais associada à saúde bucal
mesmo (Grupo I - CD, ent. 3).

Ressalta-se que havia um momento específico para planejamento conjunto e discussão de problemas do território, que correspondia à reunião de equipe, com frequência semanal, conforme protocolo da Secretaria Municipal da Saúde. Porém, tal mecanismo pareceu não desencadear processos integradores entre os profissionais da EqSB ou, pelo menos, teve reduzida capacidade de catalisar açóes compartilhadas. Diante disto, reflete-se sobre os motivos que levariam as EqSB a não agir ativamente na organizaçáo das USF ou limitarem seu campo de atuaçáo ao núcleo duro da odontologia.

Assim, a EqSB precisaria se apresentar mais proativa, mais interativa, com possibilidades, até mesmo, de liderar o processo educativo na comunidade, sem a prévia "autorizaçáo" do enfermeiro. Para tanto, precisará, entre outras coisas, compreender que saúde bucal não precisa restringir o discurso à boca, poderá falar de organização social, de problemas comunitários, de doenças emergentes ou prevalentes que estão prejudicando as pessoas, incluindo as questôes de adoecimento bucal neste contexto complexo.

Diante destas constataçôes empíricas, destaca-se a necessidade de investimento da gestão municipal em processos de educação permanente em saúde para os profissionais da rede e produçáo de coletivo. Nesta perspectiva, entende-se que há carência de processos formativos cuja temática aborde as raízes da saúde coletiva, despertando o entendimento e o interesse dos profissionais sobre o SUS e, especialmente, sobre o processo de trabalho na ESF, de forma a produzir novas subjetivaçôes que repercutam em mudança de perfil (implicado com a coisa pública e com a produção do cuidado) e não apenas no cumprimento de formalidades, metas 
e exigências ministeriais. Em alguma medida, "estudantes e movimentos populares, gestores do SUS e docentes da área da saúde estáo implicados sempre em processos de disputa ideológica que acontecem durante a formação e nos exercícios profissional e da participação" (CECCIM, 2005, p. 984).

Neste sentido, presume-se que a falta de reconhecimento do saber popular e do estímulo à participação social seja, principalmente, porque grande parte destes profissionais desconhece a potencialidade de tal prática, bem como possuem pouco contato com as experiências exitosas decorrentes da mesma na construção do SUS. Assim, a educação em serviço precisa ser uma vertente explorada no processo formativo também dos trabalhadores da saúde, mas requererá, para tanto, estratégias pedagógicas diferenciadas e metodologias ativas para ressignificar as práticas e os modelos de organização do processo de trabalho em saúde (CECCIM; FEUERWERKER, 2004; MERHY, 2005).

Apesar disso, ressalta-se que a EqSB apresentava também boa interação nas atividades interdisciplinares realizadas na área. Além do Programa Saúde na Escola (PSE), em duas das unidades visitadas, havia sido implantado grupo de tabagismo, tendo, inclusive, odontólogos como coordenadores dos mesmos. Nestes locais, os entrevistados relataram que a EqSB tentava abordar diversos temas, interagindo com os vários grupos que eram organizados pelas equipes. Destaca-se que estas unidades apresentavam o apoio matricial do Núcleo de Apoio à Saúde da Família (Nasf), sendo este um diferencial para organização das açôes na ESF.

Aqui, a gente tem o grupo do "bem viver", que é um grupo desenvolvido pela equipe do Nasf. Nós temos também um grupo, que desenvolvo, que é o grupo do tabagismo. Não é só abordado palestra de saúde bucal como, por exemplo, o grupo do tabagismo, nós abordamos os males do cigarro como um todo, é claro que a gente enfoca também a parte da saúde bucal, mas de uma forma geral (Grupo I - CD, ent. 1).

Eu acho que a gente é uma categoria que está, no processo da ESF, presente no grupo da gestante, no grupo de saúde do idoso, do "bem viver", que é um grupo de atividade física associado ao grupo hiperdia, desenvolvido pelo Nasf. A saúde bucal está sempre presente não somente nos temas relacionados à saúde bucal, mas, por exemplo, no grupo de tabagismo, que é uma dentista e uma médica que irão conduzir o grupo (Grupo I - CD, ent. 4).

As unidades com grupo de tabagismo implantado apresentavam equipe de Nasf para apoio matricial das açóes, ainda que o grupo educativo estivesse sob responsabilidade do odontólogo. Por sua vez, nem todas as USF possuíam apoio do Nasf e, justamente estas, atrelavam as atividades educativas sobre tabagismo às 
campanhas de incentivo do Ministério da Saúde, ou seja, com abordagem pontual e ritualista. Neste sentido, parece inadequado que as EqSB dependam de apoio matricial para desenvolverem uma ação desta natureza; por outro lado, revela a necessidade de processos de educação permanente e suporte de outros profissionais para impulsionar novas maneiras de lidar com a comunidade.

Apesar das limitaçôes, alguns profissionais relataram táticas para superar estas dificuldades e, assim, desenvolver ações que promovessem educação em saúde em suas comunidades.

A gente tem utilizado muito o varal da saúde, que foi a ideia de uma colega de outra unidade de saúde. Então, a gente tem um varal, que é um barbante mesmo, e a gente tem confeccionado material educativo de diversos temas para colocar no varal. Apresentamos no momento da sala de espera e, às vezes, mantemos este varal na unidade, por exemplo, semana da tuberculose, do câncer de boca, deixamos uns dois ou três dias ali exposto (Grupo I - CD, ent. 4).

Diante da fala descrita, o profissional buscava alternativas de superação das dificuldades, trazendo inovaçôes no contexto das suas atividades, fazendo uso da observação e multiplicação de experiências exitosas de outra unidade de saúde. Esta prática é uma postura bastante positiva que poderia ser utilizada por outros profissionais. Porém, questiona-se o impacto que o "varal da saúde" poderá causar nos usuários adscritos, pois as salas de espera eram realizadas na recepção; local pouco adequado para desenvolvimento das atividades. Além disso, o varal era apresentado de forma pontual e verticalizada, aparentando pouco significado para aqueles que não participaram da sua explanação.

Neste cenário, ressalta-se a conformação de um processo educativo marcado pela pedagogia da transmissão, pois entende-se o "varal da saúde" como uma prática unidirecional que favorece a reprodução do pensamento dos "educadores" sobre os "educandos", especialmente porque a escolha do tema é oportunizada por campanhas do calendário ministerial. Uma prática educativa precisa estimular a participação dos usuários para que haja desenvolvimento da sua autonomia, senso crítico e responsabilização sobre seus problemas de saúde. Quer seja uma prática inovadora, quer seja tradicional, ela terá bons efeitos no processo educativo quando suscitar reflexão aos sujeitos envolvidos (ALBUQUERQUE; STOTZ, 2004; VASCONCELOS, 2004). 


\section{Saberes e técnicas mobilizadas para construção das intervençóes educativas: transmissão de conteúdos para disciplinar os corpos}

O processo da educação em saúde caracterizou-se, ao longo do tempo, pela predominância de práticas autoritárias, alicerçadas na transmissão de informações e regras de higiene para as classes populares, que deveriam absorver acriticamente as normas e adequá-las em suas formas de andar a vida (SOUZA; JACOBINA, 2009; FALKENBERG et al., 2014).

Não obstante haja outros processos de educação em saúde em curso, a educação via transmissão de informaçóes foi uma característica predominante nas falas dos dentistas entrevistados, que, por sua vez, revelaram o caráter prescritivo e burocrático das escolhas de temas desenvolvidos na comunidade.

[...] geralmente a gente define o tema, data, confecciona cartazes, mas a palestra já está pronta, a gente nunca pediu a opinião deles [pessoas da comunidade] (Grupo I - CD, ent. 6).

Diante disto, percebeu-se a reprodução de um modelo limitado de educação em saúde centrado no profissional e que, ainda, representava a forma mais comum de abordagem pedagógica nas práticas. As EqSB, segundo entrevistados, utilizavam técnicas como palestras expositivas (na comunidade ou em sala de espera) com exibição de cartazes e modelos didáticos (peças anatômicas, instrumentos de higiene pessoal etc.). Ressalta-se, contudo, que o mais importante é a relação estabelecida no momento do encontro educativo, uma vez que uma atividade desta natureza é um processo vivo em ato, e as diferentes tecnologias sáo importantes, desde que utilizadas para produção do cuidado em saúde (MERHY, 2007).

Entretanto, não se identificou, nas falas dos dentistas, referências a atividades relacionadas ao uso de técnicas mais dialógicas como, por exemplo, a roda de conversa ou outros métodos que oportunizassem a interação com o usuário, permitindo a expressão de sua visão sobre o tema discutido, bem como espaços para questionar o conteúdo abordado.

Com relação aos temas que foram mobilizados pela EqSB para construção das intervençôes educativas nas USF, os entrevistados destacaram que os principais assuntos abordados nas suas práticas estavam relacionados aos sinais e sintomas de doenças em órgãos dentais e às técnicas de higiene, buscando alguma integração 
com as demais açôes desenvolvidas por outros profissionais da unidade e com a população da área.

Teve o dia do idoso e foi decidido fazer uma atividade com sorteio de perguntas. Quando a pergunta era de odonto, eu respondia; as perguntas da médica, ela respondia. Mas não tem aquela educação ainda, né? A gente quem fez as perguntas. Eu bolei perguntas que seriam interessantes para o idoso (Grupo I - CD, ent. 2).

Considerando que o lúdico é uma forma de desenvolver a criatividade e o conhecimento, destaca-se que esta técnica educativa é de grande relevância para as práticas da saúde bucal na ESF (SANTOS et al., 2009). Todavia, pelo fato de as perguntas serem construídas a priori pelos profissionais, o tema abordado dava poucas oportunidades aos usuários de uma participação ativa na ação proposta. Assim, apesar de o método educacional ser atraente, tal ação perdeu parte da sua potência por desenvolver-se como uma prática comum à educação bancária, pois não valorizava a curiosidade e o saber dos participantes. Ainda assim, a intençáo da ludicidade é estimular a interação entre os indivíduos, embora mais importante que a interação é o estímulo à autonomia dos sujeitos, bem como a construção conjunta do conhecimento, por meio da valorização do saber genuíno dos participantes.

Não obstante, mesmo técnicas tradicionais podem estabelecer mecanismos de maior cuidado na população, por meio da divulgação de informaçôes acerca de cuidado com sua saúde individual e coletiva. Por outro lado, a intenção deve ser a ampliação do escopo das práticas educativas, na perspectiva popular, para que se tornem mais significativas e libertadoras (VASCONCELOS, 2004)

Em contraste com as falas recorrentes que reduziram a saúde bucal ao núcleo da odontologia, um dos entrevistados relatou as açóes da EqSB articuladas a outros campos de saberes, valorizando uma prática educativa ampliada, considerando a saúde de modo integral e compreendendo que o cuidado em saúde bucal é complexo e, assim sendo, deve despertar outros sentidos.

[...] a gente faz atividades não só ligadas à odontologia, mas atividades lúdicas, atividades ligadas ao entretenimento, atividades artísticas, alguns artesanatos e, às vezes, tem dança, tem alongamento, cuida, de modo geral, da saúde integral (Grupo I - CD, ent. 4).

A saúde bucal coletiva aglutina no seu campo teórico-prático a importância do cuidado integral, enfatizando a prática de atividades que não fragmentem o corpo e que compreendam as doenças bucais como respostas de um modo de andar a vida (NARVAI; FRAZÃO, 2008). Neste sentido, o envolvimento da EqSB em atividades 
amplas como a participação em atividades físicas, em açóes de modalidade artísticas, artesanatos, entretenimento, entre outras, traz uma ressignificação do conceito da saúde bucal, favorecendo sua valorização no cenário das práticas na ESF, bem como aumentando o conhecimento do usuário sobre outras possibilidades de atuação do cirurgiáo-dentista no processo de cuidar.

Outra questão importante foi o processo de trabalho das EqSB. No distrito sanitário em estudo, notou-se que as condutas curativas estavam mais valorizadas quando comparadas às práticas preventivas. Cabe destacar que, entre as metas coletivas pactuadas pela coordenação distrital e os odontólogos das USF, apenas a escovação dental supervisionada constituía um indicador de saúde a ser alcançado.

\footnotetext{
Nossa meta é 250 escovações por mês, mas nós somos uma unidade que não possui escovódromo, sendo que a planta da nossa unidade é pequena e mal dividida. Entâo, o pai da nossa colega se disponibilizou a confeccionar um escovódromo e é esse escovódromo que acaba viabilizando que a gente aumente a meta de escovação supervisionada (Grupo I - CD, ent. 4).

Na campanha de vacinação passada, a gerente recebeu um ofício informando que era para a saúde bucal vir trabalhar. A gente vem trabalhar, mas não vem tíquete, não vem nada. $\mathrm{A}$ gente vem mesmo porque é um dia que a gente pode produzir, é um dia de escovação, de alcançar uma quantidade maior de pessoas (Grupo I - ASB, ent. 3).
}

A escovação supervisionada pode ser uma atividade de grande relevância entre as técnicas preventivas odontológicas, capaz de diminuir o impacto de doenças periodontais e perda precoce de unidades dentárias, mas numa perspectiva de continuidade e frequência, associada a melhorias da assistência clínica. No entanto, a forma pela qual estava sendo abordada e exigida, a escovação supervisionada parecia ser pouco adequada e com resolubilidade limitada. Além do mais, a escovação era estimulada por metas burocráticas, distanciando-se da real intenção, que é cuidar de pessoas, torná-las aptas ao autocuidado, desenvolver mecanismos de autoestima e, também, aumentar a troca de conhecimento entre EqSB e a comunidade.

Desta forma, entende-se que práticas de escovação não geram mudanças no cenário da saúde bucal de uma comunidade com histórico de vazio assistencial e ausência de políticas públicas essenciais (educação, moradia, saneamento etc.), sobretudo se náo estiverem atreladas a processos educativos que tragam outros significados para a população.

Não obstante, é oportuno destacar outro aspecto relevante que influenciou o processo de trabalho das $\mathrm{EqSB}$, relacionado às precárias condições de funcionamento 
em que muitos consultórios odontológicos encontravam-se nas USF. Durante as visitas às unidades de saúde, durante coleta de dados, observou-se que alguns consultórios estavam sem funcionamento, decorrente de problemas estruturais (falta de peças para manutenção, falhas em alguns instrumentos, equipamento quebrado etc.) e que, por sua vez, dependiam de empresas terceirizadas (contratadas pela Secretaria Municipal de Saúde) para sua reparação. Em algumas situaçóes, também foi observada ausência de insumos essenciais que comprometiam o andamento adequado das atividades clínicas. Nota-se, assim, a frustração para o profissional da EqSB realizar seus serviços cotidianos, sendo um desafio diário trabalhar na realidade inadequada a que estavam submetidos.

Cobram [os gestores] bastante a questão da produção, da gente alcançar metas, isso é bem cobrado. Inclusive, agora, a gente tem uma gratificação variável, que vai depender do alcance das metas. A gente sempre tem reuniōes com o dentista distrital, mas sempre dentro do respeito (Grupo I - CD, ent. 7).

Eu só vejo mais a cobrança. Esse mês a produtividade foi baixa, a gente tá 15 dias sem o teste bacteriológico, pois a incubadora quebrou e a secretaria não mandou outra, mas pediram um relatório para justificar por que a produtividade foi baixa. Eu acho que a Secretaria e o Distrito Sanitário cobram mais do que apoiam as açóes da saúde bucal (Grupo I - ASB, ent. 3).

Nesta perspectiva, por um lado, as EqSB eram obrigadas a cumprirem metas, por outro, não recebiam condições favoráveis para este cumprimento. Além disso, é importante destacar que tal situação fragiliza o vínculo do profissional com os usuários que procuram por seus serviços e, muitas vezes, encontram apenas uma escova como resposta a suas necessidades. Há, nesta situação corriqueira, uma reversão da produção do cuidado, pois o ato terapêutico necessário à resolução de um problema é substituído por uma ação paliativa, ou seja, tanto profissional quanto usuários são capturados por uma lógica que atesta contra a valorização e resolubilidade do trabalho no SUS.

Os profissionais pontuaram, também, que existia baixo investimento do governo municipal nas açôes da educação em saúde, quando referente à produção de cartazes, folders e folhetos para esclarecimento da população sobre as atividades de saúde bucal desenvolvidas na área. Eles destacaram que o material educativo disponibilizado estava vinculado ao PSE, com o qual eram fornecidos macromodelos da anatomia dental, doenças prevalentes, arcada dentária e escova. 
Enquanto isso, visando a qualificar suas açôes educativas, parte dos entrevistados destacou que foi preciso confeccionar os materiais didáticos para que as atividades não se resumissem a discursos. Contudo, o custeio desses materiais era assumido com recursos financeiros dos próprios profissionais.

Somos nós que confeccionamos esses materiais (didáticos), eles não são fornecidos pela gestão. Nós temos que buscar, procurar alguma forma, até mesmo para que os pacientes se interessem pelo que a gente está fazendo e, muitas vezes, esses recursos são, na grande maioria, trazidos por nós, profissionais (Grupo I - CD, ent. 7).

A questâo do apoio com material educativo, com recursos mesmo, tá muito difícil, tá complicado. A gente tá passando por um momento que os carros que tem no distrito, tem um agendamento e, às vezes, a gente agenda uma atividade educativa na nossa equipe mais distante, que precisa de carro, com um mês de antecedência. A gente convida a comunidade, planeja tudo, quando chega no dia ou na véspera, o carro não aparece. Aí, a equipe de certa forma vai sendo desacreditada (Grupo I - CD, ent. 4).

Diante destas falas, houve convergência de opinióes dos profissionais sobre o distanciamento da gestão no apoio às atividades educativas. Dentre as situaçôes críticas, destaca-se a falta de transportes disponíveis em momento oportuno para deslocamentos dos profissionais para áreas distantes. Além disso, os usuários disponibilizavam espaços físicos, os ACS divulgavam as açôes em estabelecimentos comerciais, bem como realizavam convites individuais durante as visitas domiciliares. No entanto, devido à distância entre USF e algumas localidades, os profissionais precisavam de suporte para deslocamento. Quando estas atividades eram canceladas por inviabilidade do transporte, os prejuízos eram grandes, trazendo frustração para profissionais e usuários.

Em divergência, outros entrevistados relataram que recebiam material didático para suas ações na grande maioria das vezes que solicitaram, tendo suporte da Secretaria de Saúde e do distrito.

Utilizamos folder, cartaz que a secretaria sempre manda para gente, quando solicitamos. A gente sempre está sendo atendido. Datashow também, a gente prepara slide, entendeu? Então assim, eles tão dando todo apoio que a gente precisa (Grupo II, ent. 1).

As enfermeiras passam para mim com bastante antecedência, para que eu possa pedir datashow, tudo que a gente puder fazer para ajudar nas atividades educativas, banner, cartazes, panfletos, entâo tudo que a gente puder fazer, a gente programa com antecedência com o distrito e pede tudo que o distrito possa ajudar para a gente fazer. Na maioria das vezes, a gente consegue tudo (Grupo II, ent. 2). 
As divergências das falas sinalizam que as açôes educativas atravessavam momentos conflituosos, mas os mais prejudicados eram os usuários. Além disso, constatou-se que as falas que convergiram sobre acesso e disponibilidade aos materiais e recursos didáticos para as atividades educativas partiram exclusivamente dos sujeitos que exerciam cargo de gerência nas USF. Neste sentido, cabe salientar que os gerentes das unidades de saúde, em sua totalidade, apresentavam vínculos precários, empossados segundo critérios estabelecidos por gestor municipal.

Contudo, nota-se também que os discursos convergiram na centralização de práticas educativas dependentes da utilização de equipamentos, muitas vezes, pré-fabricados e moldados segundo intençôes daqueles que direcionavam as açôes educativas. Nesta perspectiva, entende-se que a utilização de tecnologias duras (distribuição de folders, uso de cartazes, datashow etc.) durante as práticas apresentam uma racionalidade instrumental que pode, se não utilizada de maneira habilidosa, reduzir o sentido da própria ação educativa.

Assim sendo, a mediação do processo educativo não deve limitar seu desenvolvimento à existência de tais equipamentos, pois educar é transcender os limites palpáveis do aprendizado, utilizando, para isto, ferramentas que expressam a subjetividade do processo, como a valorização da dialogicidade e a problematização do cotidiano.

\section{Consideraçôes finais}

O debate acerca das responsabilidades sociais das EqSF e, por conseguinte, das EqSB é sempre carreado de nuances de difícil análise. Primeiramente, considera-se que as práticas das equipes no âmbito da APS precisam abarcar açôes na perspectiva da integralidade, ou seja, necessitam ofertar um cardápio de atividades preventivas e curativas de maneira equilibrada, mas que, sobretudo, consigam dar respostas adequadas às demandas das pessoas que precisam de cuidado.

Por sua vez, as demandas são socialmente construídas e, neste sentido, não representam essencialmente as necessidades de saúde de uma populaçáo que, por indução mercadológica ou, ainda, pela indisponibilidade histórica dos procedimentos odontológicos curativos, acumularam problemas assistenciais que não podem ser desprezados. Por este aspecto, os usuários tornam as unidades de saúde da família um lócus de busca por ações curativas (de repercussão imediata e "palpável”), em 
detrimento, inclusive, das açóes de cunho promocional (que requerem mudança de estilo de vida e nem sempre perceptíveis a curto prazo).

Para complexificar os desafios às açôes educativas em saúde, há ainda a formação inadequada dos profissionais que, incluindo os cirurgióes-dentistas, muitas vezes não valorizam os serviços públicos para produçâo do cuidado, especializam-se precocemente e marginalizam os cuidados que exigem mobilização comunitária (SANTOS et al., 2006). Na via oposta, há profissionais comprometidos, que tiveram formação coerente com a APS e estão engajados com o processo de aumento do grau de autonomia das pessoas, mas que se deparam com um cotidiano de trabalho composto por problemas na infraestrutura, no apoio institucional e matricial de outros profissionais ou dos gestores, e que acabam sucumbindo ao status quo do modelo centrado no procedimento.

A educação em saúde é uma estratégia que se alia aos atributos de uma APS abrangente e centrada nas pessoas para enfrentamento das necessidades individuais e coletivas, na perspectiva de diminuir as iniquidades. Portanto, equipes que não realizam rotineiramente açóes educativas (promoção de saúde e prevenção de doenças) aproximam-se de uma APS seletiva e, grosso modo, foi a modelagem mais aparente nos achados deste estudo. Nesta perspectiva, a categoria "Táticas para envolvimento da comunidade nas práticas de educação em saúde no fazer cotidiano das Equipes de Saúde Bucal" reforçou a incipiência das açôes educativas no território ao identificar os modos de fazer dos profissionais no cotidiano do processo de trabalho: atividades pouco dialógicas e planejamento verticalizado das açóes educativas. Outrossim, as táticas para ampliar tais açôes não se apresentaram com vigor para transformação do modelo biomédico, estando centradas na comunidade por meio do Programa Saúde na Escola, dependentes do apoio matricial do Nasf e reféns do protagonismo do enfermeiro na definição de temas.

Deste modo, as estratégias institucionais presentes no processo de trabalho das EqSB foram tímidas ou não lograram a mudança do modelo de atenção à saúde, pois estavam pautadas em mecanismos comuns à educação bancária. Por sua vez, as táticas para contornar os entraves não mostraram potência para romper os desafios e, por vezes, foram inócuas na construçáo de modelos alternativos de educação popular.

$\mathrm{Na}$ mesma direção, a categoria "Saberes e técnicas mobilizadas para construção das intervençôes educativas: transmissão de conteúdos para disciplinar os corpos" amplificou tal constatação, especialmente pelo caráter prescritivo e burocrático 
das escolhas de temas e do trabalho centrado em procedimentos clínicos. Todavia, aspectos organizativos também implicavam a dificuldade ou motivação profissional para realização de açóes educativas frequentes e abrangentes: baixo incentivo (financeiro e material) dos gestores; cobrança administrativa por procedimentos clínicos ou educativos de cunho instrumental (escovação e número de palestras), além da falta de apoio na formação permanente dos profissionais para incorporação de modelos didáticos que colocam a comunidade em primeiro plano.

Por fim, as desigualdades marcantes na população impóem desafios às EqSB que transcendem sua governabilidade. Nesta órbita, imersos na teia dos inúmeros problemas sociais, a educação em saúde, como prática das equipes, apresenta-se como uma possiblidade de ampliação das intervençôes, mas muito aquém da sua potência para redefinição de modos de andar a vida. ${ }^{2}$

\section{Referências}

ALBUQUERQUE, P. C.; STOTZ, E. N. A educação popular na atenção básica à saúde no município: em busca da integralidade. Interface: comunicação, saúde, educação. Botucatu, v. 8, n. 15, p. 259-274, 2004.

ALMEIDA FILHO, N.; JUCÁ, V. Saúde como ausência de doença: crítica à teoria funcionalista de Christopher Boorse. Ciência \& Saúde Coletiva. Rio de Janeiro, v. 7, n. 4, p. 879-889, 2002. ALVES, V. S. Um modelo de educação em saúde para o Programa Saúde da Família: pela integralidade da atenção e reorientação do modelo assistencial. Interface: comunicação, saúde, educação. Botucatu, v. 9, n. 16, p. 39-52, 2005.

AYRES, J. R. C. M. Cuidado: trabalho e interação nas práticas de saúde. Rio de Janeiro: Abrasco, 2009.

BOTAZZO, C. Sobre a bucalidade: notas para a pesquisa e contribuições ao debate. Ciência \& Saúde Coletiva. Rio de Janeiro, v. 11, n. 1, p. 7-17, 2006.

BOURDIEU, P. Os usos sociais da ciência: por uma sociologia clínica do campo científico. São Paulo: Unesp, 2004.

BRANDÃO, C. R. O que é educação? São Paulo: Editora Brasiliense, 2004.

CAMPOS, G. W. S.; CUNHA, G. T.; FIGUEIREDO, M. D. Práxis e formação Paideia: apoio e cogestão em saúde. São Paulo: Hucitec, 2013.

CECCIM, R. B. Educação permanente em saúde: descentralização e disseminação de capacidade pedagógica na saúde. Ciência \& Saúde Coletiva. Rio de Janeiro, v. 10, n. 4, p. 975-986, 2005. 
CECCIM, R. B.; FEUERWERKER, L. C. M. O quadrilátero da formação para a área da saúde: ensino, gestão, atenção e controle social. Physis: Revista de Saúde Coletiva. Rio de Janeiro, v. 14, n. 1, p. 41-65, 2004.

COELHO, M. T. A. D.; ALMEIDA FILHO, N. Normal-patológico, saúde-doença: revisitando Canguilhem. Physis: Revista de Saúde Coletiva. Rio de Janeiro, v. 9, n. 1, p. 13-36, 1999.

CONRAD, P. The medicalization of society: on the transformation of human conditions into treatable disorders. Baltimore: The Johns Hopkins University Press, 2007.

FALKENBERG, M. B. et al. Educação em saúde e educação na saúde: conceitos e implicaçóes para a saúde coletiva. Ciência \& Saúde Coletiva. Rio de Janeiro, v. 19, n. 3, p. 847-852, 2014.

FLICK, U. Qualidade na pesquisa qualitativa. Porto Alegre: Bookman, 2009.

FONTANELLA, B. J. B. et al. Amostragem em pesquisas qualitativas: proposta de procedimentos para constatar saturação teórica. Caderno de Saúde Pública. Rio de Janeiro, v. 27, n. 2, p. 389-394, 2011.

FREIRE, P. Medo e ousadia: o cotidiano do professor. 13a ed. São Paulo: Paz e Terra, 2011a. . Pedagogia do oprimido. 50a ed. Rio de Janeiro: Paz e Terra, $2011 \mathrm{~b}$.

GAZZINELLI, M. F. et al. Educação em saúde: conhecimentos, representaçóes sociais e experiências da doença. Cadernos de Saúde Pública. Rio de Janeiro, v. 21, n. 1, p. 200-206, 2005.

L'ABBATE, S. Educação em saúde: uma nova abordagem. Cadernos de Saúde Pública. Rio de Janeiro, v. 10, n. 4, p. 481-490, 1994.

MENDES, E. V. O Distrito Sanitário: o processo social de mudança das práticas sanitárias do Sistema Único de Saúde. São Paulo-Rio de Janeiro: Hucitec-Abrasco, 1993.

MERHY, E. E. Em busca do tempo perdido: a micropolítica do trabalho vivo em saúde. In: MERHY, E. E.; ONOCKO, R. (Orgs.). Agir em saúde: um desafio para o público. São Paulo: Hucitec, 2007. p. 71-112.

. O desafio que a educação permanente tem em si: a pedagogia da implicação. Physis: Revista de Saúde Coletiva. Rio de Janeiro, v. 9, n. 16, p. 161-177, 2005.

MINAYO, M. C. S. O desafio do conhecimento: pesquisa qualitativa em saúde. São Paulo: Hucitec, 2014.

NARVAI, P. C.; FRAZÃO, P. Saúde Bucal no Brasil: muito além do céu da boca. Rio de Janeiro: Fiocruz, 2008.

PAGLIOSA, F. L.; ROS, M. A. O relatório Flexner: para o bem e para o mal. Revista Brasileira de Educaçâo Médica. Rio de Janeiro, v. 32, n. 4, p. 492-499, 2008.

PAIM, J. S. Modelos de Atenção à Saúde no Brasil. In: GIOVANELLA, Ligia et al. Política e sistemas de saúde no Brasil. 2a ed. Rio de Janeiro: Fiocruz, 2012. p. 547-573. 
PINHEIRO, R.; CECCIM, R. B.; MATTOS, R. A. (Orgs.). Ensinar saúde: a integralidade e o SUS nos cursos de graduação na área da saúde. Rio de Janeiro: Abrasco, 2006.

RODRIGUES, A. A. A. O.; ASSIS, M. M. A. Saúde bucal no Programa de Saúde da Família: sujeitos, saberes e práticas. Vitória da Conquista: UESB, 2009.

SALVADOR. Secretaria Municipal de Saúde. Plano Municipal de Saúde de Salvador - 20142017. Salvador, 2014.

SANTOS, A. M. et al. A produção de sentidos sobre a saúde bucal: do lúdico à realidade. Revista de APS. v. 12, n. 4, p. 420-429, 2009.

. Mercado de trabalho e a formação dos estudantes de odontologia: o paradigma da mudança. Revista Saude.com. Jequié, v. 2, n. 2, p. 169-182, 2006.

SANTOS, A. M.; ASSIS, M. M. A. Saúde bucal: da fragmentação à integralidade. Feira de Santana: UEFS, 2010.

SOUZA, T. M. S.; RONCALli, A. G. Saúde bucal no Programa Saúde da Família: uma avaliação do modelo assistencial. Cadernos de Saúde Pública. Rio de Janeiro, v. 23, n. 11, p. 2727-2739, 2007.

SOUZA, I. P. M. A.; JACOBINA, R. R. Educação em saúde e suas versôes na história brasileira. Revista Baiana Saúde Pública. Salvador, v. 33, n. 4, p. 618-627, 2009.

TESSER, C. D. (Org.). Medicalizaçâo social e atenção à saúde no SUS. São Paulo: Hucitec, 2010. . Medicalização social: o excessivo sucesso do epistemicípio moderno na saúde. Interface: comunicação, saúde, educação. Botucatu, v. 10, n. 19, p. 61-76, 2006.

TESSER, C. D; PEZZATO, L. M.; SILVA, E. N. Medicalização social e odontologia: possíveis aproximações. Saúde e Sociedade. São Paulo, v. 24, n. 4, p. 1349-1361, 2015.

VASCONCELOS, E. M. Educação popular: de uma prática alternativa a uma estratégia de gestão participativa das políticas de saúde. Physis: Revista de Saúde Coletiva. Rio de Janeiro, v. 14, n. 1, p. 67-83, 2004.

YIN, R. K. Estudo de caso: planejamento e métodos. Porto Alegre: Bookman, 2005.

\section{Notas}

${ }^{1}$ Trata-se de pesquisa resultante de dissertação de Mestrado Profissional em Saúde Coletiva, Universidade Estadual de Feira de Santana, Bahia. Não há conflitos de interesse.

${ }^{2}$ P. R. da C. Brasil realizou a pesquisa de campo, análise dos dados e escrita do artigo. A. M. dos Santos orientou a pesquisa e realizou a revisão do artigo. 


\section{Abstract}

\section{Challenges of oral health teams educational activities in Primary Health Care: tactics, knowledge and techniques}

Study on the educational practices of Oral Health Teams, members of the Primary Health Care in Salvador, Bahia state, Brazil. The research aimed to analyze the tactics used by Oral Health Teams for community involvement in health education programs and discuss pedagogical practices (knowledge and techniques) developed in educational activities. Qualitative approach was carried out by using 22 semistructured interviews involving seven dentists, seven oral health assistants, six managers of health facilities and two district managers. Thematic content analysis guided the outcomes discussion. The educational model was centered on dentist's knowledge, revealed in prescriptive and bureaucratic nature of the activities in the community. Such educational practices tend not to encourage the users' autonomy, making them, in a sense, hostage to the hegemonic model of care focused on disease.

Keywords: health education; oral health; Family Health Strategy; local health systems; Primary health care; education. 